\title{
Helicobacter pylori infection downregulates duodenal CFTR and SLC26A6 expressions through TGF $\beta$ signaling pathway
}

Guorong Wen ${ }^{1,2,3}$, Shili Deng ${ }^{1,2,3}$, Wenfeng Song ${ }^{4,5}$, Hai Jin ${ }^{1,2,3}$, Jingyu Xu ${ }^{1,2,3}$, Xuemei Liu ${ }^{1,2,3}$, Rui Xie ${ }^{1,2,3}$, Penghong Song ${ }^{4,5}$ and Biguang Tuo ${ }^{1,2,3^{*}}$ (i)

\begin{abstract}
Background: The pathogenesis of Helicobacter pylori (H. pylori) infection-induced duodenal ulcer remains to be elucidated. Duodenal mucosal bicarbonate secretion is the most important protective factor against acid-induced mucosal injury. We previously revealed that $\mathrm{H}$. pylori infection downregulated the expression and functional activity of duodenal mucosal cystic fibrosis transmembrane conductance regulator (CFTR) and solute linked carrier 26 gene family A6 (SLC26A6) which are the two key duodenal mucosal epithelial cellular bicarbonate transporters to mediate duodenal bicarbonate secretion. In this study, we investigated the mechanism of H. pylori infectioninduced duodenal CFTR and SLC26A6 expression downregulation.
\end{abstract}

Results: We found that $H$. pylori infection induced the increase of serum transforming growth factor $\beta$ (TGF $\beta$ ) level and duodenal mucosal TGF $\beta$ expression and the decrease of duodenal mucosal CFTR and SLC26A6 expressions in C57 BL/6 mice. The results from the experiments of human duodenal epithelial cells (SCBN) showed that H. pylori increased TGF $\beta$ production and decreased CFTR and SLC26A6 expressions in SCBN cells. TGF $\beta$ inhibitor SB431542 reversed the H. pylori-induced CFTR and SLC26A6 expression decreases. The further results showed that TGF $\beta$ directly decreased CFTR and SLC26A6 expressions in SCBN cells. TGF $\beta$ induced the phosphorylation of p38 mitogen-activated protein kinase (MAPK) and P38 MAPK inhibitor SB203580 reversed the TGF $\beta$-induced CFTR and SLC26A6 expression decreases.

Conclusions: H. pylori infection downregulates duodenal epithelial cellular CFTR and SLC26A6 expressions through TGF $\beta$-mediated P38 MAPK signaling pathway, which contributes to further elucidating the pathogenesis of H. pyloriassociated duodenal ulcer.

Keywords: Duodenal ulcer, Helicobacter pylori, CFTR, SLC26A6, TGF $\beta$

\section{Background}

Duodenal ulcer is a common disease in the digestive tract $[1,2]$. It has been demonstrated that Helicobacter pylori (H. pylori) infection is main etiologic agent responsible for duodenal ulcerogenesis $[1,3,4]$. In spite of extensive studies, the pathogenesis of $H$. pylori infection-induced duodenal ulcer remains to be elucidated.

Duodenal mucosal bicarbonate secretion is the most important protective factor against acid-induced

\footnotetext{
* Correspondence: tuobiguang@aliyun.com

${ }^{1}$ Department of Gastroenterology, Affiliated Hospital, Zunyi Medical College, 149 Dalian Road, Zunyi 563003, China

${ }^{2}$ Digestive Disease Institute of Guizhou Province, Zunyi, China

Full list of author information is available at the end of the article
}

duodenal mucosal injury $[5,6]$. A clinical study showed that there was significant diminished duodenal mucosal bicarbonate secretion in the patients with $H$. pylori-associated duodenal ulcer in comparison with healthy controls, and duodenal mucosal bicarbonate secretion returned to normal levels after the eradication of $\mathrm{H}$. pylori [7]. The studies from animal experiments showed that intraluminal perfusion of $H$. pylori water extract inhibited acid-stimulated duodenal mucosal bicarbonate secretion in rats [8]. Prostaglandin E2 (PGE2)-stimulated murine duodenal mucosal bicarbonate secretion in vitro was also strongly inhibited by water extract from cytotoxin-associated gen A (CagA) /vacuolating cytotoxin

(c) The Author(s). 2018 Open Access This article is distributed under the terms of the Creative Commons Attribution 4.0 International License (http://creativecommons.org/licenses/by/4.0/), which permits unrestricted use, distribution, and 
A (VacA)-positive H. pylori strains [9]. These studies suggest that the effect of $H$. pylori on duodenal mucosal bicarbonate secretion might be involved in the pathogenesis of $H$. pylori-associated duodenal ulcer. However, the mechanisms whereby $H$. pylori influences duodenal mucosal bicarbonate secretion are not completely understood.

Duodenal mucosal bicarbonate secretion is mediated by bicarbonate transporting proteins located in duodenal mucosal epithelial cells. The cystic fibrosis transmembrane conductance regulator (CFTR) and solute linked carrier 26 gene family A6 (SLC26A6) are the two key bicarbonate transporting proteins of duodenal mucosal epithelial cells and they play important role in the regulation of duodenal mucosal bicarbonate secretion [1012]. We previously showed that $H$. pylori infection downregulated the expression and functional activity of duodenal mucosal CFTR and SLC26A6 [13], which contributes to the development of duodenal ulcer. In this study, we investigated the mechanism of $H$. pylori infection-induced duodenal CFTR and SLC26A6 expression downregulation. We hope to further elucidate the mechanisms whereby $H$. pylori infection influences duodenal mucosal $\mathrm{HCO}_{3}{ }^{-}$secretion and the pathogenesis of H. pylori infection-induced duodenal ulcer.

\section{Methods}

\section{Reagents}

Prostaglandin $\mathrm{E}_{2}\left(\mathrm{PGE}_{2}\right)$ and forskolin were purchased from Sigma. pH-sensitive fluorescent dye, 2',7'-bis(2-carboxyethyl)-5(6)-carboxy-fluorescein acetoxymethyl ester (BCECF-AM), was from Invitrogen. Anti-CFTR, anti-SLC26A6, anti-P38, anti-phospho-P38, and anti- $\beta$-actin antibodies were from Santa Cruz. All other chemicals in solutions were obtained from Sigma and Calbiochem.

\section{H. pylori strain}

H. pylori strain (ATCC 43504), from the H. pylori Strain Pool, Beijing, China, was verified to be cytotoxin-associated gen A (CagA)- and vacuolating cytotoxin A (VacA)-positive previously [14] and used throughout the experiments. The CagA and VacA s1/s2 and $\mathrm{m} 1 / \mathrm{m} 2$ genotypes of the $H$. pylori strain were further confirmed by specific polymerase chain reaction (PCR) as described previously by Miernyk et al. [15] The H. pylori strain was routinely cultured for $48 \mathrm{~h}$ on Brucella agar plates containing $5 \%$ sheep blood at $37{ }^{\circ} \mathrm{C}$ under microaerophilic conditions in a humidified $\mathrm{CO}_{2}$ incubator (Thermo Fisher Scientific, Wilmington, DE) and then used for experiments.

\section{H. pylori infection of mice}

Male C57 BL/6 mice of 6 to 8 weeks from Shanghai Animal Center (Chinese Academy of Science, Shanghai, China) were used in this study. The animal experiments were approved by the Experimental Animal Ethics Committee of Zunyi Medical College and conducted in accordance with principles stated in the Guide for the Care and Use of Laboratory Animals (NIH publication 8623, National Institutes of Health, Bethesda, MD, 1985). The mice were housed in the experimental animal facility with specific pathogen free (SPF) of Zunyi Medical College under standard care conditions. 60 mice were used for $H$. pylori infection experiments and 10 mice were used as controls. After a week of acclimatization, the mice were orally gavaged with $0.5 \mathrm{ml} \mathrm{H}$. pylori suspension in Brucella broth $(1 \times$ $10^{9} \mathrm{CFU} / \mathrm{ml}$ ) once daily for 4 consecutive days. The control mice were only gavaged with sterile Brucella broth. The mice were sacrificed by cervical dislocation under $\mathrm{CO}_{2}$ narcosis at 4 week after last gavage. Blood samples were quickly obtained by cardiac puncture for serum transforming growth factor $\beta$ (TGF $\beta$ ) level examination. The gastric antrum tissues were used for $H$. pylori infection examination. The duodenal mucosal tissues were used for examination of CFTR and SLC26A6 mRNA and protein expressions and TGF $\beta$ mRNA expression.

The presence of $H$. pylori in the stomach was determined by Giemsa-stained sections. H. pylori-negative was defined when Giemsa staining was determined to be negative by visual observation, and $H$. pylori-positive was defined when positive Giemsa staining was observed. H. pylori infection density was assessed by semiquantitative analysis of $H$. pylori levels in the gastric mucosa $(+$, less than 10 bacteria per gland;,++ 10 to 20 bacteria in at least one gland; +++, 20 to 30 bacteria in at least one gland; ++++ , more than 30 bacteria in at least one gland).

\section{H. pylori infection of duodenal epithelial cells}

SCBN (a gift from Dr. Hui Dong in University of California San Diego) is a nontumorigenic duodenal epithelial cell line obtained from a human patient [16]. SCBN cells were maintained in Dulbecco's modified Eagle's medium (DMEM) supplemented with $10 \%$ fetal calf serum and $50 \mathrm{mg} / \mathrm{ml}$ penicillin-streptomycin for two days. Then $5 \times 10^{6}$ SCBN cells were seeded on six-well plates and grown at $37{ }^{\circ} \mathrm{C}$ in a $5 \% \mathrm{CO}_{2}$ atmosphere. Prior to infection, each well was washed twice in $1 \mathrm{ml}$ of antibiotic-free cell culture medium. Then $H$. pylori was added to the cultured cells at different multiplicity of infection (MOI). After incubation for $24 \mathrm{~h}$ at $37{ }^{\circ} \mathrm{C}$ in a $5 \% \mathrm{CO}_{2}$ atmosphere, the cells were harvested for examination of CFTR and SLC26A6 protein expression levels. The supernatants were for examination of TGF $\beta$ concentration. For intracellular $\mathrm{pH}$ measurement, SCBN cells were grown on 12-mm round coverslips and then incubated with $H$. pylori at a MOI value of 400 for $24 \mathrm{~h}$. 
In addition, an uninfected control was included in each experiment.

\section{Measurement of TGF $\beta$ concentration}

For the measurement of serum TGF $\beta$ concentration, after blood was quickly obtained by cardiac puncture, the blood sample was centrifuged immediately at $3000 \mathrm{rpm}$ for $5 \mathrm{~min}$ for collection of serum. The serum sample was stored at $-20{ }^{\circ} \mathrm{C}$ and analyzed within one week. Serum TGF $\beta$ level was detected by using the enzyme-linked immunosorbent assay kit (ELISA) (TGF $\beta 1$ Mouse Uncoated ELISA Kit, Invitrogen, USA,
Cat. No. 88-50,690-22) according to the manufacturer's instructions. TGF $\beta$ level in supernatant of $H$. pylor$i$-infected SCBN cells was detected by using TGF $\beta 1$ Human Uncoated ELISA Kit (Invitrogen, USA, Cat. No. 88-50,390-77).

\section{Quantitative real-time reverse transcription PCR analysis for mRNA expressions of CFTR, SLC26A6, and TGF $\beta$}

Total RNA extract of murine duodenal mucosal tissues and quantitative real-time reverse transcription PCR analysis were performed as described previously [17]. The mRNA expression level of CFTR, SLC26A6, or

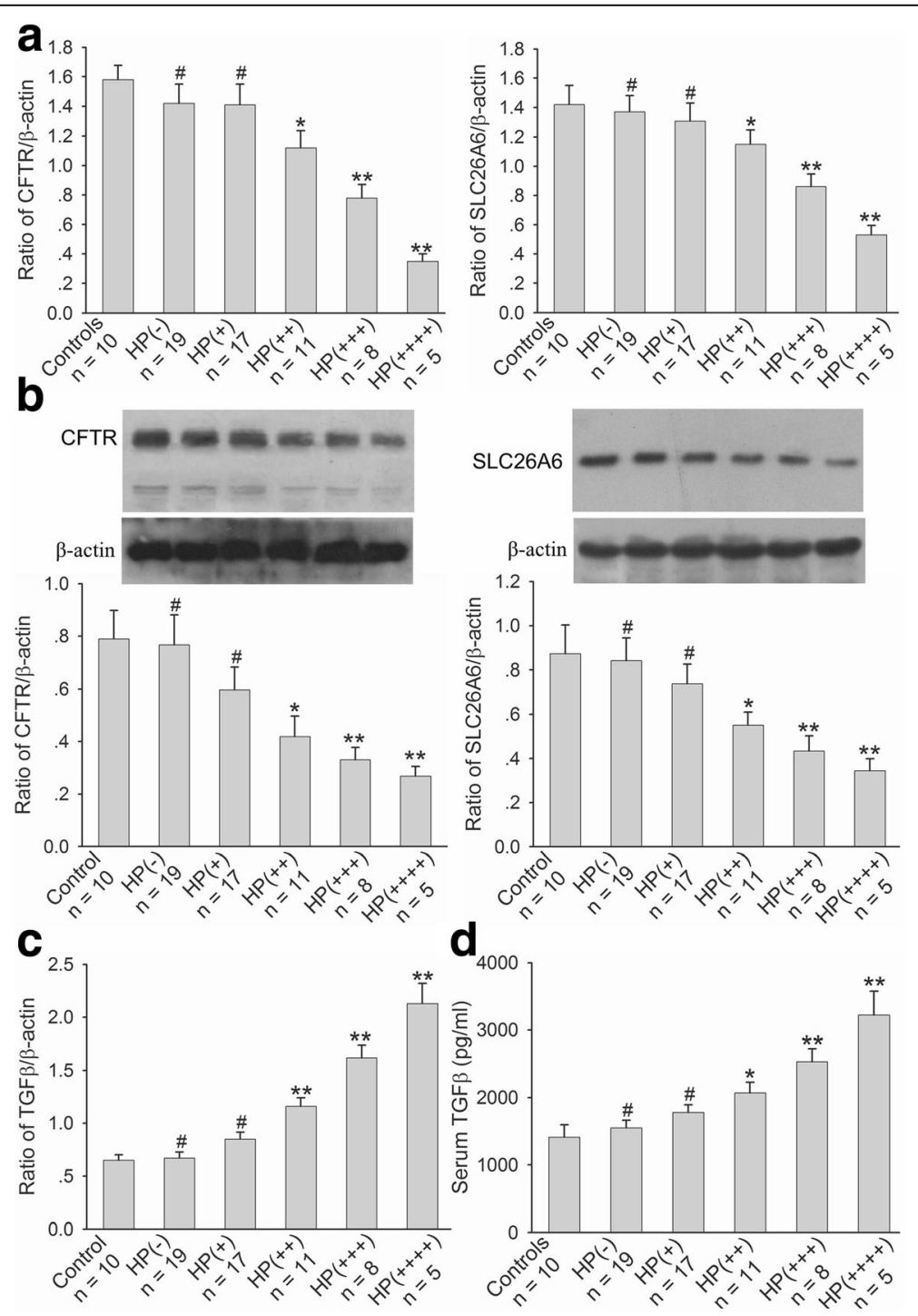

Fig. 1 Effect of H. pylori infection on CFTR and SLC26A6 mRNA and protein expressions and TGF $\beta$ mRNA expression in murine duodenal mucosa and murine serum TGF $\beta$ level. Murine H. pylori-infected model was established as described in experimental procedures. a: Effect of $H$. pylori infection on CFTR and SLC26A6 mRNA expressions in murine duodenal mucosa. b: Effect of H. pylori infection on CFTR and SLC26A6 protein expressions in murine duodenal mucosa. Upper panels are representative blots and lower panels are the comparisons of expression levels between groups. c: Effect of $H$. pylori infection on TGF $\beta$ mRNA expression in murine duodenal mucosa. $\mathbf{d}$ : Effect of $H$. pylori infection on murine serum TGF $\beta$ level. Values are mean $\pm \mathrm{SE}$ in each series. Global $P<0.01 ;{ }^{\#} P>0.05,{ }^{*} P<0.05,{ }^{* *} P<0.01$ compared to controls 
TGF $\beta$ was normalized to that of $\beta$-actin and was expressed as a ratio relative to $\beta$-actin. The primers were as follows: CFTR, forward 5'-AAGGCGGCCTATAT GAGGTT-3' and reverse 5'-AGGACGATTCCGTT GATGAC-3'; SLC26A6, forward 5'-GGTGGTGAA GCTGTTGAATGAC-3' and reverse 5'-ATGTTGCCC ACGACATCTACCTC-3'; TGF $\beta$, forward 5' -ATAC GCCTGAGTGGCTGTC-3' and reverse $5^{\prime}$-GCCC TGTATTCCGTCTCCT-3'; $\beta$-actin, forward $5^{\prime}$-CTGC CTGACGGCCAAGTC-3' and reverse 5'-CAAGAAGG AAGGCTGGAAAAGA-3'.

\section{Western blot analysis for CFTR, SLC26A6, P38, and Phospho-P38 expressions}

Murine duodenal mucosal tissues or SCBN cells were homogenized in lysis buffer at $4{ }^{\circ} \mathrm{C}$ and western blot analysis was performed as described previously [18]. Anti-CFTR, anti-SLC26A6, anti-P38, anti-Phospho-P38, or anti- $\beta$-actin (served as internal control) was used as primary antibody. The results were expressed as the ratio relative to $\beta$-actin.

\section{Measurement of duodenal epithelial cellular bicarbonate secretion}

Bicarbonate secretion in SCBN cells was determined through the measurement of intracellular $\mathrm{pH}[\mathrm{pHi}]$ by using $\mathrm{pH}$-sensitive fluorescent dye BCECF-AM as described previously [19]. When forskolin or PGE2 was used, forskolin $(10 \mu \mathrm{M}), \mathrm{PGE}_{2}(1 \mu \mathrm{M})$, or control was added into solution. Stimulated duodenal epithelial cellular bicarbonate secretion was to stimulated peak pHi value minus basal $\mathrm{pHi}$ value and expressed as $\Delta \mathrm{pHi}$.

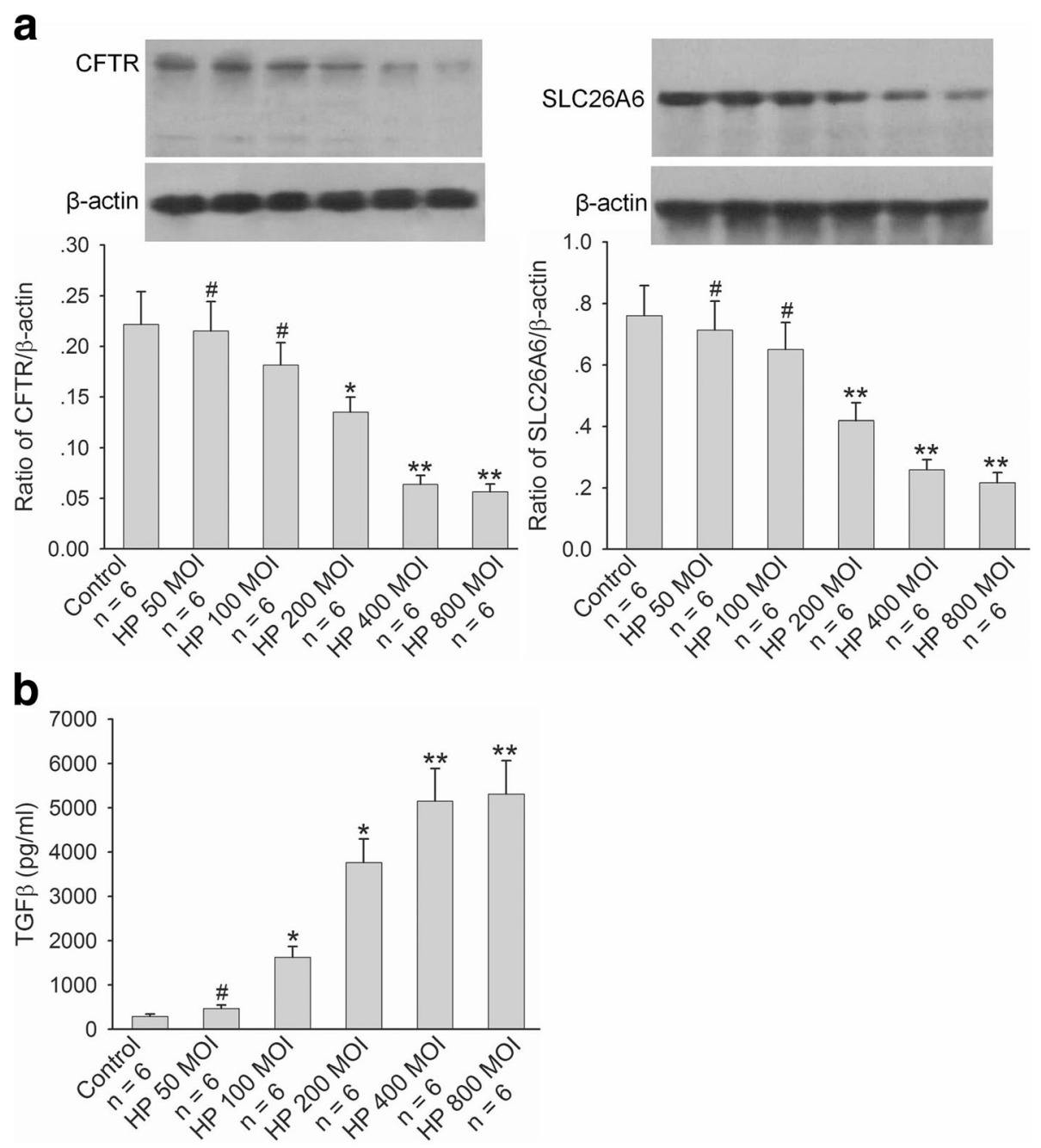

Fig. 2 Effect of H. pylori infection on CFTR and SLC26A6 protein expressions and TGF $\beta$ production in SCBN cells. SCBN cells were treated with different $\mathrm{MOI}$ of $\mathrm{H}$. pylori for $24 \mathrm{~h}$ as described in experimental procedures. a: Effect of $\mathrm{H}$. pylori infection on CFTR and SLC26A6 protein expressions in SCBN cells. Upper panels are representative blots and lower panels are the comparisons of expression levels between groups. $\mathbf{b}$ : Effect of $H$. pylori infection on TGF $\beta$ production in SCBN cells. Values are mean \pm SE in each series. Global $P<0.01 ; \# P>0.05,{ }^{*} P<0.05$, **P $P<0.01$ compared to controls 


\section{Statistics}

Statistical analysis was processed by using the SPSS PC statistic package. All results are expressed as means \pm standard errors (SE). Data were analyzed by one-way analysis of variance (ANOVA) followed by Newman-Keul's post-hoc test or, when appropriate, by the two-tailed student $\mathrm{t}$ tests. $P<0.05$ was considered statistically significant.

\section{Results}

Effect of $H$. pylori infection on CFTR, SLC26A6 and TGF $\beta$ expressions in murine duodenal mucosa and TGF $\beta$ level in murine serum

We first established $H$. pylori infection model in mice. Among 60 experimental mice, 19 (31.67\%) were $H$. pylori (-), 17 (28.33\%) were H. pylori $(+), 11$ (18.33\%) were H. pylori $(++), 8(13.33 \%)$ were $H$. pylori $(+++)$, and 5
(8.33\%) were $H$. pylori $(++++)$. The results from PCR and western blot analyses showed that the mRNA and protein expressions of duodenal mucosal CFTR and SLC26A6 in the mice with $H$. pylori $(-)$ and (+) were not altered in comparison with controls, but there were markedly decrease in the mice with $H$. pylori $(++),(++$ $+)$, and $(++++)$. The mRNA and protein expressions of duodenal mucosal CFTR and SLC26A6 were decreased with the severity of $H$. pylori infection (Fig. $1 \mathrm{a}$ and b). The further results showed that duodenal mucosal TGF $\beta$ mRNA expression in the mice with $H$. pylori $(-)$ and $(+)$ was not altered in comparison with controls and there were markedly increase in the mice with $H$. pylori $(++)$, $(+++)$, and $(++++)$. The duodenal mucosal TGF $\beta$ mRNA expression was increased with the severity of $H$. pylori infection (Fig. 1c). H. pylori infection in the mice also induced serum TGF $\beta$ concentration increase. The change
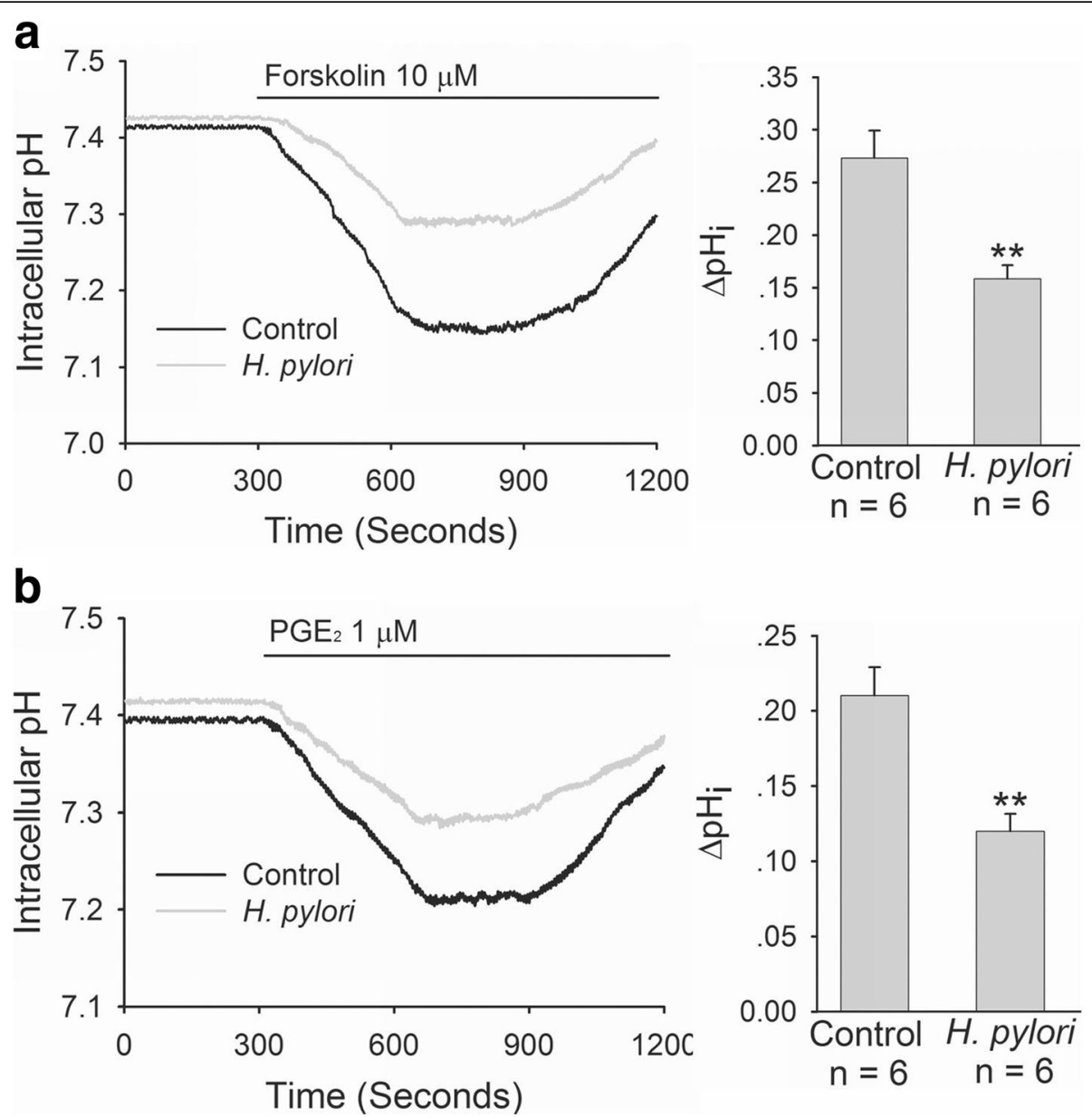

Fig. 3 Effect of $H$. pylori infection on forskolin- and $\mathrm{PGE}_{2}$-stimulated bicarbonate secretion in SCBN cells. SCBN cells were treated with $H$. pylori at a $\mathrm{MOI}$ value of 400 for $24 \mathrm{~h}$. The measurement of bicarbonate secretion in SCBN cells was performed as described in experimental procedures. $\mathbf{a}$ : Effect of H. pylori infection on forskolin- stimulated bicarbonate secretion in SCBN cells. Left panel is time course of change of forskolin-stimulated intracellular $\mathrm{pH}(\mathrm{pHi})$ in SCBN cells. Right panel is the comparison of $\triangle \mathrm{pHi}$. $\mathbf{b}$ : Effect of $\mathrm{H}$. pylori infection on $\mathrm{PGE}_{2}$-stimulated bicarbonate secretion in SCBN cells. Left panel is time course of change of $\mathrm{PGE}_{2}$-stimulated intracellular $\mathrm{pH}(\mathrm{pHi}$ ) in SCBN cells. Right panel is the comparison of $\triangle \mathrm{pHi}$. Values are mean $\pm \mathrm{SE}$ in each series. ${ }^{* *} \mathrm{P}<0.01$ compared to controls 
of serum TGF $\beta$ level was in consistent with the change of TGF $\beta$ expression in duodenal mucosa and serum TGF $\beta$ level was also increased with the severity of $H$. pylori infection (Fig. 1d). These results demonstrate that H. pylori infection decreases duodenal mucosal CFTR and SLC26A6 expressions and increases duodenal mucosal TGF $\beta$ expression, implying that duodenal mucosal CFTR and SLC26A6 decreases may be related to duodenal mucosal TGF $\beta$ increase.

\section{Effect of $H$. pylori infection on CFTR and SLC26A6} expressions and TGF $\beta$ production in duodenal epithelial cells

We further selected human duodenal epithelial cells, SCBN, to do experiments and investigated the effect of H. pylori on CFTR and SLC26A6 expressions and TGF $\beta$ production in duodenal epithelial cells. As shown in Fig. 2, after incubation with SCBN cells for $24 \mathrm{~h}, \mathrm{H}$. pylori induced significant decrease of CFTR and SLC26A6 protein expressions in SCBN cells at a MOI value of 200 in comparison with controls and induced the maximal decrease at a MOI value of 400 (Fig. 2a). In addition, $H$. pylori induced TGF $\beta$ production increase in SCBN cells MOI-dependently. Likewise, H. pylori induced significant TGF $\beta$ production increase in SCBN cells at a MOI value of 200 in comparison with controls and induced the maximal increase at a MOI value of 400 (Fig. 2b). Forskolin, adenylate cyclase activator, is a known CFTR activator and stimulates duodenal mucosal bicarbonate secretion through CFTR, whereas $\mathrm{PGE}_{2}$ is believed to stimulate duodenal mucosal bicarbonate secretion mainly through SLC26A6 [20]. The further results showed that forskolin- and $\mathrm{PGE}_{2}$-stimulated bicarbonate secretions were markedly decreased in $H$. pylori-infected SCBN cells in comparison with controls (Fig. 3). TGF $\beta$ inhibitor SB431542 $(10 \mu \mathrm{M})$ reversed $H$. pylori-induced CFTR and SLC26A6 protein expression decreases in SCBN cells (Fig. 4). These results indicate that $H$. pylori infection downregulates duodenal epithelial cellular CFTR and SLC26A6 expressions through TGF $\beta$ signaling.

\section{Effect of TGF $\beta$ on CFTR and SLC26A6 expression in duodenal epithelial cells}

We further investigated whether TGF $\beta$ could regulate CFTR and SCL26A6 expressions in duodenal epithelial cells directly. As shown in Figs. 5 and 6, after TGF $\beta$ (5 ng/ $\mathrm{ml}$ ) incubated with SCBN cells for $24 \mathrm{~h}$, CFTR and SLC26A6 protein expressions (Fig. 5) and forskolin- and $\mathrm{PGE}_{2}$-stimulated bicarbonate secretions (Fig. 6) in SCBN cells were markedly decreased in comparison with controls. The further results showed that TGF $\beta(5 \mathrm{ng} / \mathrm{ml})$
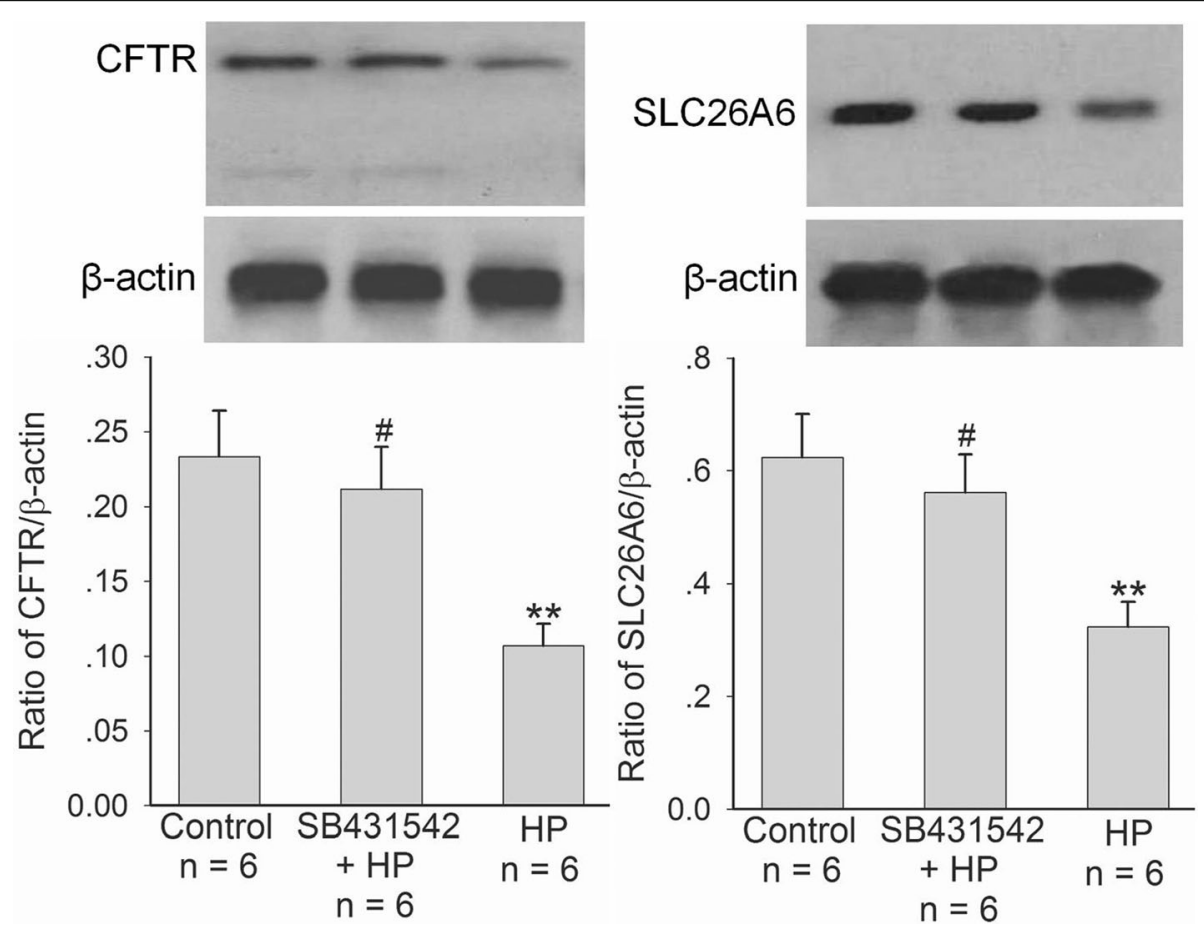

Fig. 4 Effect of TGF $\beta$ inhibition on H. pylori-induced CFTR and SLC26A6 protein expression decreases in SCBN cells. SCBN cells were treated with H. pylori at a MOI value of 400 for $24 \mathrm{~h}$. TGF $\beta$ inhibitor SB431542 (10 $\mu \mathrm{M})$ was added at 10 min before H. pylori. Upper panels are representative blots and lower panels are the comparisons of expression levels between groups. Values are mean \pm SE in each series. ${ }^{\#} P>0.05,{ }^{* *} P<0.01$ compared to controls 

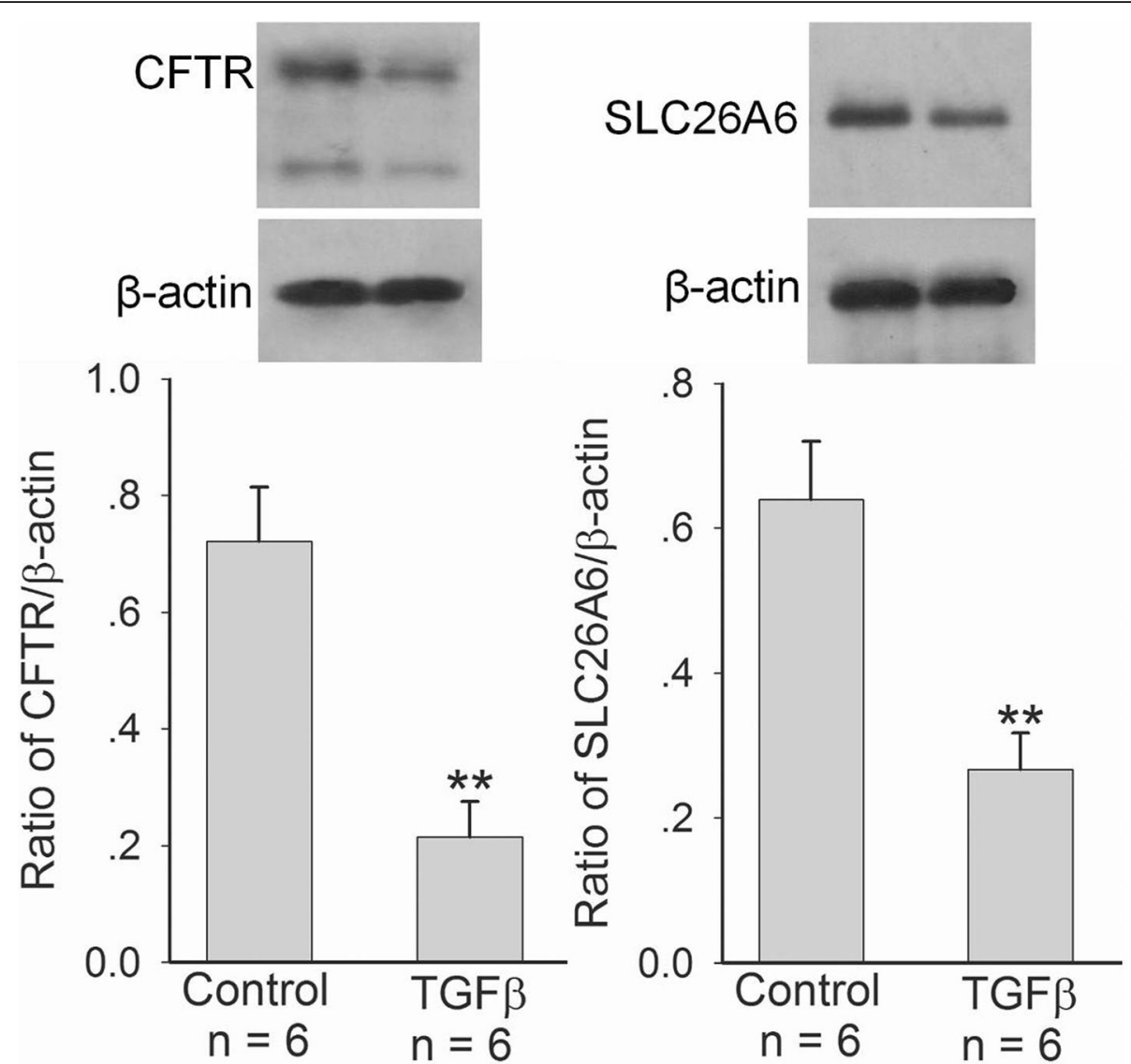

Fig. 5 Effect of TGF $\beta$ on CFTR and SLC26A6 protein expressions in SCBN cells. SCBN cells were treated with TGF 3 (5 ng/ml) for $24 \mathrm{~h}$. Upper panels are representative blots and lower panels are the comparisons of expression levels between groups. Values are mean \pm SE in each series. **P $P 0.01$ compared to controls

induced the phosphorylation of P38 mitogen-activated protein kinase (MAPK) in SCBN cells after incubation with SCBN cells for $0.5 \mathrm{~h}$ and the maximal response was reached at $2 \mathrm{~h}$ (Fig. 7a). P38 MAPK inhibitor SB203580 $(10 \mu \mathrm{M})$ markedly attenuated TGF $\beta$-induced CFTR and SLC26A6 expression decreases in SCBN cells (Fig. 7b). The results demonstrate that TGF $\beta$ downregulates duodenal epithelial cellular CFTR and SLC26A6 expressions through P38 MAPK signaling pathway.

\section{Discussion}

Duodenal mucosal bicarbonate secretion is the most important protective factor against acid-induced duodenal mucosal injury. In this study, we provide evidence that H. pylori infection downregulates the expressions of two key bicarbonate transport proteins, CFTR and SLC26A6, in duodenal epithelial cells through TGF $\beta$-mediated P38 MAPK signaling pathway.

H. pylori is a Gram-negative bacterium and more than $50 \%$ of people were infected with $H$. pylori in the world [21]. It has been demonstrated that $H$. pylori infection is a major cause of duodenal ulcerogenesis $[1,3,4]$. However, the mechanisms whereby $H$. pylori infection causes duodenal ulcerogenesis are not completely understood. Previous studies revealed that $H$. pylori influenced duodenal mucosal bicarbonate secretion which might be involved in the pathogenesis of $H$. pylori-associated duodenal ulcer [7-9]. Our recent study further revealed that $H$. pylori infection downregulated CFTR and SLC26A6 expressions in human duodenal mucosal epithelial cells and the CFTR and SLC26A6 expression decreases were related to the severity and virulent factors of $H$. pylori infection [13]. But, how H. pylori influences CFTR and SLC26A6 is not clear. Several pathogenic mechanisms, including $H$. pylori virulence factors and host factors, have been associated with $H$. pylori-induced gastroduodenal diseases. In particular, the immune response against $H$. pylori virulence factors might provide a linkage to the development of gastroduodenal diseases [22-24]. Cytokines have long been considered as the main mediators of the immune response to $H$. pylori infection, which could modulate various intracellular 

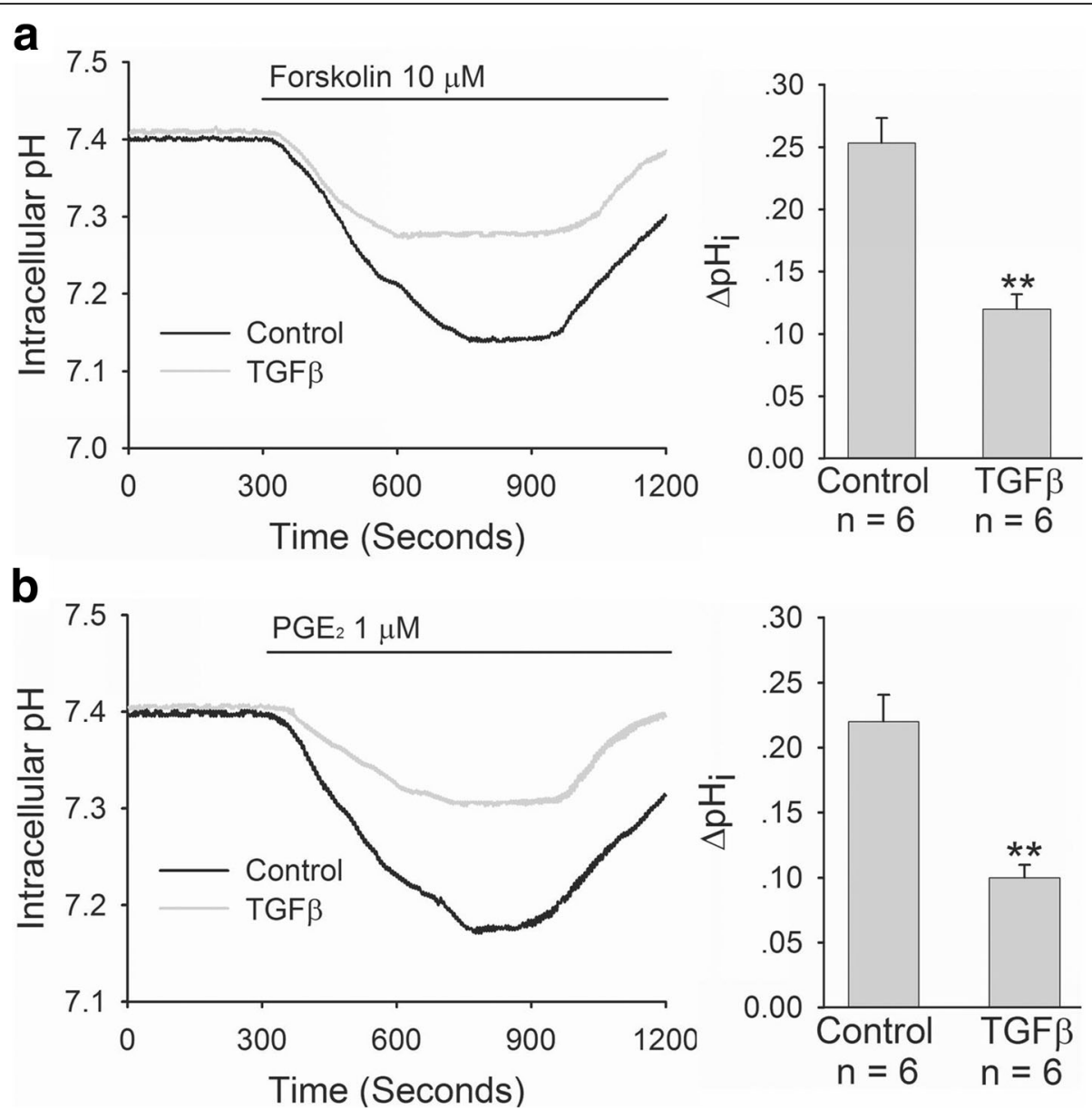

Fig. 6 Effect of TGF $\beta$ on forskolin- and PGE 2 -stimulated bicarbonate secretions in SCBN cells. SCBN cells were treated with TGF $\beta$ (5 ng/ml) for $24 \mathrm{~h}$. The measurement of bicarbonate secretion in SCBN cells was performed as described in experimental procedures. a: Effect of TGF $\beta$ on forskolinstimulated bicarbonate secretion in SCBN cells. Left panel is time course of change of forskolin-stimulated intracellular pH (pHi) in SCBN cells. Right panel is the comparison of $\triangle \mathrm{pHi}$. $\mathbf{b}$ : Effect of TGF $\beta$ on $P \mathrm{PGE}_{2}$-stimulated bicarbonate secretion in SCBN cells. Left panel is time course of change of $\mathrm{PGE}_{2}$-stimulated intracellular $\mathrm{pH}$ (pHi) in SCBN cells. Right panel is the comparison of $\triangle \mathrm{pHi}$. Values are mean $\pm \mathrm{SE}$ in each series. ${ }^{*} P<0.01$ compared to controls

signaling pathways and reprogram host gene expression $[25,26]$.

In this study, we hypothesized that H. pylori might regulate duodenal CFTR and SLC26A6 expressions through cytokines. First, we selected cytotoxin-associated gen A (CagA)- and vacuolating cytotoxin A (VacA)-positive $H$. pylori strain to establish murine $H$. pylori infection model. We found that $H$. pylori infection downregulated duodenal mucosal CFTR and SLC26A6 expressions in mice, which depended on the severity of $H$. pylori infection. On the other hand, $H$. pylori infection induced the increase of serum TGF $\beta$ level and duodenal mucosal TGF $\beta$ mRNA expression in the mice, which also depended on the severity of $H$. pylori infection. It suggested that a correlation might exist between CFTR and SLC26A6 expressions and TGF $\beta$ in duodenal mucosa. We further selected SCBN cells to perform experiments, because SCBN cells are nontransformed duodenal epithelial cells derived from humans and widely used for the study of bicarbonate secretion $[14,27]$. The results showed that $H$. pylori increased TGF $\beta$ production and decreased CFTR and SLC26A6 expressions in SCBN cells, which depended on multiplicity of infection of $H$. pylori. Moreover, forskolinand $\mathrm{PGE}_{2}$-stimulated bicarbonate secretions were markedly decreased in $H$. pylori-infected SCBN cells in comparison with controls. It has been demonstrated that forskolin stimulates duodenal mucosal bicarbonate secretion through CFTR and $\mathrm{PGE}_{2}$-stimulated duodenal mucosal bicarbonate secretion is SLC26A6-dependent [20]. The results further supported that $H$. pylori decreased duodenal epithelial cellular CFTR and SLC26A6 expressions. Further results showed that TGF $\beta$ inhibitor SB431542 reversed the $H$. pylori-induced CFTR and SLC26A6 expression decreases. After incubation with SCBN cells for $24 \mathrm{~h}$, 
a

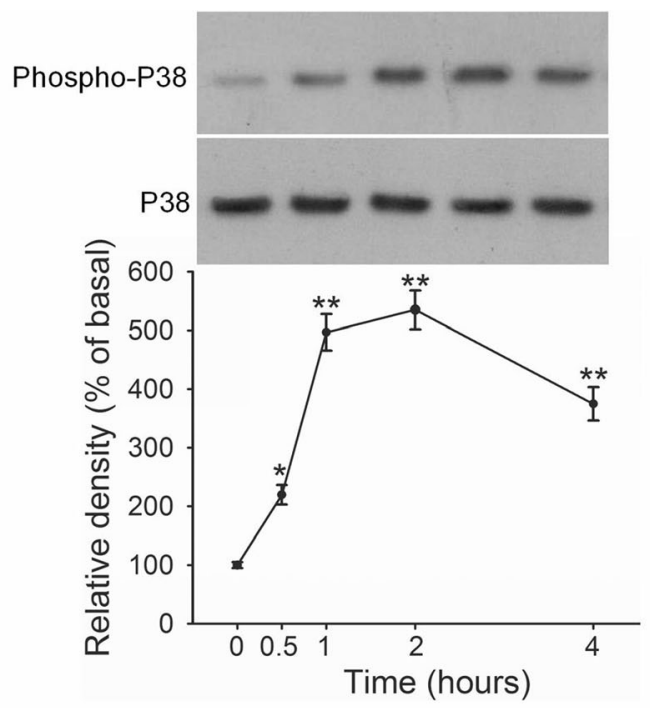

b
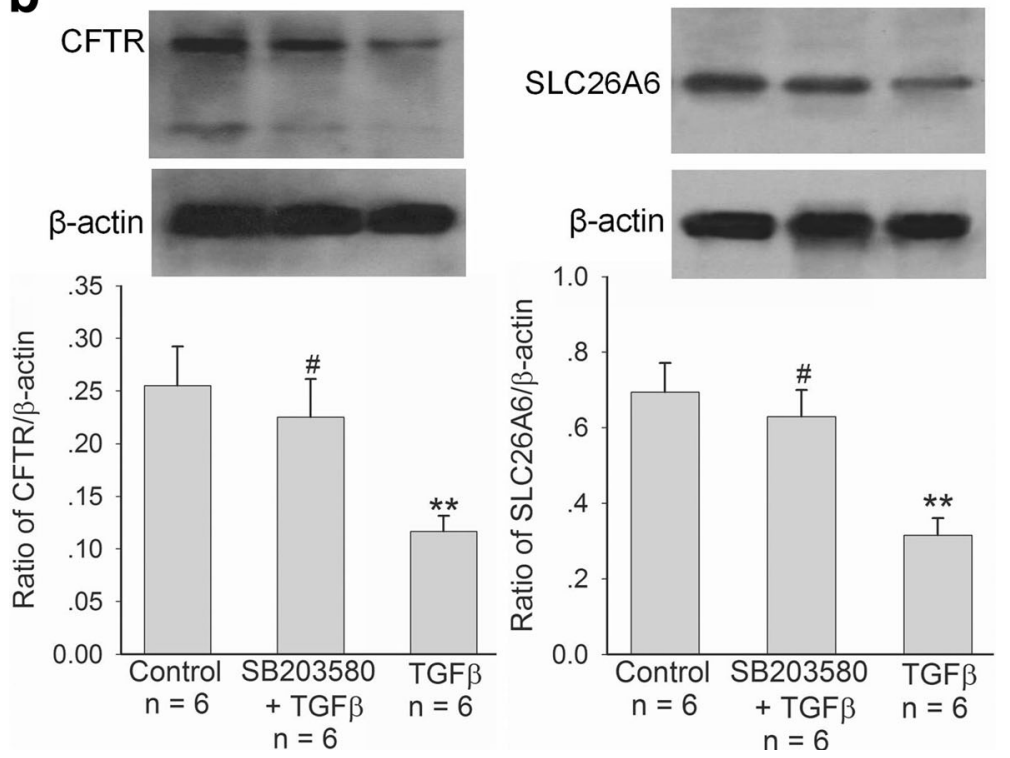

Fig. 7 Role of P38 MAPK in TGF $\beta$-induced CFTR and SLC26A6 protein expression decreases in SCBN cells. SCBN cells were treated with TGF $\beta$ $(5 \mathrm{ng} / \mathrm{ml})$ for $24 \mathrm{~h}$. P38 MAPK inhibitor SB203580 $(10 \mu \mathrm{M})$ was added at $30 \mathrm{~min}$ before TGF $\beta$. a: Effect of TGF $\beta$ on P38 phosphorylation in SCBN cells. Upper panels are representative blots and lower panels are time course of TGF $\beta$-induced P38 phosphorylation. $\mathbf{b}$ : Effect of P38 MAPK inhibition on TGF $\beta$-induced CFTR and SLC26A6 protein expression decreases in SCBN cells. Upper panels are representative blots and lower panels are the comparisons of expression levels between groups. Values are mean $\pm \mathrm{SE}$ in each series. ${ }^{*} P>0.05,{ }^{* *} P<0.01$ compared to controls

TGF $\beta$ directly decreased duodenal epithelial cellular CFTR and SLC26A6 expressions by itself and forskolinand $\mathrm{PGE}_{2}$-stimulated bicarbonate secretions were also markedly decreased in TGF $\beta$-treated SCBN cells in comparison with controls. Taken together, these results demonstrate that $H$. pylori downregulates duodenal epithelial cellular CFTR and SLC26A6 expressions through TGF $\beta$ signaling pathway.

TGF $\beta$ is a multifunctional cytokine that exerts a wide range of biological activities. TGF $\beta$ signaling regulates many different cell functions and critical cellular processes. Changes in cellular behavior are governed by activation of TGF $\beta$ rectors which triggers subsequent signaling pathways that change gene expression $[28,29]$. Previous studies have provided evidence that TGF $\beta$ downregulates CFTR expression in polarized T84 human colonocytes and in primary human-airway epithelial cells [30-32]. As a cytokine, TGF $\beta$ can be induced through a number of cell types, such as macrophages and lymphocytes. H. pylori infection can cause the activation of immune cells, including macrophages, $\mathrm{T}$ cells, and $\mathrm{B}$ cells, leading to the production of cytokines. Previous studied have revealed that serum TGF $\beta$ level is elevated in patients with $H$. pylori-associated gastritis and 
peptic ulcers, in comparison with $H$. pylori-negative patients [33]. TGF $\beta$ mRNA expression is significantly increased in gastric mucosal biopsies of $H$. pylori-infected patients in comparison with $H$. pylori-uninfected patients [34]. In one study, H. pylori-secreted soluable proteins stimulated TGF $\beta$ production in gastric and colonic epithelial cells [35]. These studies indicate that $H$. pylori infection induces TGF $\beta$ production increase and TGF $\beta$ signaling might be involved in the pathogenesis of $H$. pylori-associated gastroduodenal diseases. In this study, our results showed that $H$. pylori infection increased TGF $\beta$ production and decreased CFTR and SLC26A6 expressions in duodenal epithelial cells. TGF $\beta$ inhibition reversed H. pylori infection-induced CFTR and SLC26A6 expression decreases, which demonstrates that $H$. pylori infection downregulates duodenal mucosal epithelial cellular CFTR and SLC26A6 expressions through TGF $\beta$ signaling, revealing the potential etiological role of TGF $\beta$ in H. pylori-associated duodenal ulcer.

How does TGF $\beta$ regulate duodenal mucosal epithelial cellular CFTR and SLC26A6 expressions? TGF $\beta$ is a complex signaling molecule that is activated when TGF $\beta$ binds to the TGF $\beta$ receptors, then leading to the activation and phosphorylation of the downstream mediators Smad proteins and regulating the expression of target genes in cooperation with other transcription factors, co-activators and co-repressors [28, 36]. In addition to Smad-dependent signaling, the binding of TGF $\beta$ to its receptors also activates many noncanonical signaling pathways, including p38 MAPK, external signal-regulated kinase (ERK), and c-Jun N-terminal kinase (JNK) signaling pathways $[37,38]$. In this study, our results showed that TGF $\beta$ induced the phosphorylation of P38 MAPK in SCBN cells and the inhibition of P38 MAPK reversed the TGF $\beta$-induced CFTR and SLC26A6 expression decreases in SCBN cells, which demonstrates that TGF $\beta$ downregulates CFTR and SLC26A6 expressions in duodenal epithelial cells through P38 MAPK signaling pathway.

\section{Conclusions}

The findings from this study demonstrate that $H$. pylori infection downregulates duodenal epithelial cellular CFTR and SLC26A6 expressions through TGF $\beta$-mediated P38 MAPK signaling pathway. CFTR and SLC26A6 are the two key bicarbonate transporters responsible for duodenal mucosal bicarbonate secretion. This study clarifies the mechanism whereby $H$. pylori infection induces duodenal epithelial cellular CFTR and SCL26A6 expression decreases and contributes to further elucidating the pathogenesis of $H$. pylori-associated duodenal ulcer.

\section{Abbreviations}

BCECF-AM: 2',7'-bis(2-carboxyethyl)-5(6)-carboxy-fluorescein acetoxymethyl ester; CagA: cytotoxin-associated gen A; CFTR: cystic fibrosis transmembrane conductance regulator; H. pylori: Helicobacter pylori; MAPK: mitogen- activated protein kinase; $\mathrm{PGE}_{2}$ : Prostaglandin $\mathrm{E}_{2} ; \mathrm{pHi}$ : intracellular $\mathrm{pH}$; SLC26A6: solute linked carrier 26 gene family A6; TGF $\beta$ : transforming growth factor $\beta$; VacA: vacuolating cytotoxin A

\section{Funding}

This work was supported by National Natural Science Foundation of China to B. Tuo (81160054), G. Wen (81460112), and P. Song (81272675 and 81570575). The funding body had no role in the design of the study and collection, analysis, and interpretation of data and in writing this manuscript.

\section{Availability of data and materials}

All data generated and/or analysed during this study are included in this published article. The raw data used and/or analysed during this study can be found in the computer of our laboratory, which are available from the corresponding author on reasonable request.

\section{Authors' contributions}

GW, SD, WS, the acquisition and analysis of the data; HJ, JX, XL, RX, the acquisition of the data; PS, analysis of the data; BT, design of the study, analysis of the data, writing of the manuscript. All authors have read and approved the manuscript, and ensure that this is the case.

\section{Ethics approval}

The animal experiments were approved by the Experimental Animal Ethics Committee of Zunyi Medical College and conducted in accordance with principles stated in the Guide for the Care and Use of Laboratory Animals (NIH publication 8623, National Institutes of Health, Bethesda, MD, 1985).

Consent for publication

Not applicable.

\section{Competing interests}

The authors declare that they have no competing interests.

\section{Publisher's Note}

Springer Nature remains neutral with regard to jurisdictional claims in published maps and institutional affiliations.

\section{Author details}

'Department of Gastroenterology, Affiliated Hospital, Zunyi Medical College, 149 Dalian Road, Zunyi 563003, China. ${ }^{2}$ Digestive Disease Institute of Guizhou Province, Zunyi, China. ${ }^{3}$ Clinical Medical Research Center of Guizhou Province for Digestive Diseases, Zunyi, China. ${ }^{4}$ Key Laboratory of Combined Multi-organ Transplantation, Ministry of Public Health, First Affiliated Hospital, School of Medicine, Zhejiang University, Hangzhou, China. ${ }^{5}$ Collaborative innovation center for Diagnosis treatment of infectious diseases, First Affiliated Hospital, School of Medicine, Zhejiang University, Hangzhou, China.

Received: 4 September 2017 Accepted: 9 August 2018

Published online: 17 August 2018

\section{References}

1. Graham DY. History of helicobacter pylori, duodenal ulcer, gastric ulcer and gastric cancer. World J Gastroenterol. 2014;20:5191-204.

2. Quan S, Frolkis A, Milne K, Molodecky N, Yang H, Dixon E, Ball CG, Myers RP, Ghosh S, Hilsden R, van Zanten SV, Kaplan GG. Upper-gastrointestinal bleeding secondary to peptic ulcer disease: incidence and outcomes. World J Gastroenterol. 2014;20:17568-77.

3. Schöttker B, Adamu MA, Weck MN, Brenner H. Helicobacter pylori infection is strongly associated with gastric and duodenal ulcers in a large prospective study. Clin Gastroenterol Hepatol. 2012;10:487-93.

4. Venerito M, Malfertheiner P. Interaction of Helicobacter pylori infection and nonsteroidal anti-inflammatory drugs in gastric and duodenal ulcers. Helicobacter. 2010;15:239-50.

5. Allen A, Flemstrom G. Gastroduodenal mucus bicarbonate barrier: protection against acid and pepsin. Am J Physiol Cell Physiol. 2004;288:C1-19.

6. Said H, Kaji I, Kaunitz JD. Gastroduodenal mucosal defense mechanisms. Curr Opin Gastroenterol. 2015;31:486-91.

7. Hogan DL, Rapier RC, Dreilinger A, Koss MA, Basuk PM, Weinstein WM, Nyberg LM, Isenberg J. Duodenal bicarbonate secretion: eradication of 
Helicobacter pylori and duodenal structure and function in humans. Gastroenterology. 1996;110:705-16.

8. Fandrinks L, Bothmer CV, Johansson B, Holm M, Bolin I, Pettersson A. Water extract of Helicobacter pylori inhibits duodenal mucosal alkaline secretion in anesthetized rats. Gastroenterology. 1997;113:1570-5.

9. Tuo BG, Sellers ZM, Smith AJ, Barrett KE, Isenberg Jl, Dong H. A role for CagANacA in Helicobacter pylori inhibition of murine duodenal mucosal bicarbonate secretion. Dig Dis Sci. 2004;49:1845-52.

10. Mount DB, Romero MF. The SLC26 gene family of multifunctional anion exchangers. Pflugers Arch. 2004;447:710-21.

11. Seidler U. Gastrointestinal $\mathrm{HCO}_{3}{ }^{-}$transport and epithelial protection in the gut: new techniques, transport pathways and regulatory pathways. Curr Opin Pharmacol. 2013;13:900-8.

12. Sheppard DN, Welsh MJ. Structure and function of the CFTR chloride channel. Physiol Rev. 1999;79:S23-45.

13. Wen G, Jin H, Deng S, Xu J, Liu X, Xie R, Tuo B. Effects of Helicobacter pylori infection on the expressions and functional activities of human duodenal mucosal bicarbonate transport proteins. Helicobacter. 2016;21:536-47.

14. Ohkusa T, Okayasu I, Miwa H, Ohtaka K, Endo S, Sato N. Helicobacter pylori infection induces duodenitis and superficial duodenal ulcer in Mongolian gerbils. Gut. 2003;52:797-803

15. Miernyk K, Morris J, Bruden D, McMahon B, Hurlburt D, Sacco F, Parkinson A, Hennessy T, Bruce M. Characterization of Helicobacter pylori cagA and vacA genotypes among Alaskans and their correlation with clinical disease. J Clin Microbiol. 2011;49:3114-21.

16. Pang G, Buret A, O'Loughlin E, Smith A, Batey R, Clancy R. Immunologic, functional, and morphological characterization of three new human small intestinal epithelial cell lines. Gastroenterology. 1996; 111:8-18.

17. Xie $R$, Xu J, Wen $G$, Jin $H$, Liu X, Yang $Y$, Ji B, Jiang $Y$, Song P, Dong H, Tuo B. The $P 2 Y 2$ nucleotide receptor mediates the proliferation and migration of human hepatocellular carcinoma cells induced by ATP. J Biol Chem. 2014; 289:19137-49

18. Xu J, Xie R, Liu X, Wen $G$, Jin $H$, Yu Z, Jiang $Y$, Zhao Z, Yang $Y$, Ji B, Dong $H$, Tuo $B$. Expression and functional role of vacuolar $\mathrm{H}^{+}$-ATPase in human hepatocellular carcinoma. Carcinogenesis. 2012;33:2432-40.

19. Xu J, Ji B, Wen G, Yang $Y$, Jin $H$, Liu X, Xie R, Song W, Song P, Dong $\mathrm{H}$, Tuo B. $\mathrm{Na}^{+} / \mathrm{H}^{+}$exchanger $1, \mathrm{Na}^{+} / \mathrm{Ca}^{+}$exchanger 1 and calmodulin complex regulates interleukin 6-mediated cellular behavior of human hepatocellular carcinoma. Carcinogenesis. 2016;37:290-300.

20. Tuo B, Riederer B, Wang Z, Colledge WH, Soleimani M, Seidler U. Involvement of the anion exchanger SLC26A6 in PGE2- but not forskolin-stimulated duodenal bicarbonate secretion. Gastroenterology. 2006;130:349-58.

21. Eusebi LH, Zagari RM, Bazzoli F. Epidemiology of Helicobacter pylori infection. Helicobacter. 2015;19(Suppl 1):1-5.

22. Ibraghimov A, Pappo J. The immune response against Helicobacter pylori-a direct linkage to the development of gastroduodenal disease. Microbes Infect. 2000;2:1073-7

23. Moyat $M$, Velin D. Immune responses to helicobacter pylori infection. World J Gastroenterol. 2014;20:5583-93.

24. Walduck A, Andersen LP, Raghavan S. Inflammation, immunity, and vaccines for helicobacter pylori infection. Helicobacter. 2015;20(Suppl 1):17-25.

25. Figueiredo CA, Marques CR, Costa Rdos S, da Silva HB, Alcantara-Neves NM. Cytokines, cytokine gene polymorphisms and helicobacter pylori infection: friend or foe? World J Gastroenterol. 2014;20:5235-43.

26. Li N, Xie C, Lu NH. Transforming growth factor- $\beta$ : an important mediator in helicobacter pylori-associated pathogenesis. Front Cell Infect Microbiol. 2015;5:77

27. Dong X, Ko KH, Chow J, Tuo B, Barrett KE, Dong H. Expression of acidsensing ion channels in intestinal epithelial cells and their role in the regulation of duodenal mucosal bicarbonate secretion. Acta Physiol. 2011; 201:97-107.

28. Ikushima H, Miyazono K. TGF $\beta$ signalling: a complex web in cancer progression. Nature Rev. 2010;10:415-24.

29. Papageorgis P. TGF $\beta$ signaling in tumor initiation, epithelial-tomesenchymal transition, and metastasis. J Oncol. 2015;587193.

30. Howe KL, Wang A, Hunter MM, Stanton BA, McKay DM. TGF $\beta$ downregulation of the CFTR: a means to limit epithelial chloride secretion. Exp Cell Res. 2004;298:473-84.

31. Snodgrass SM, Cihil KM, Cornuet PK, Myerburg MM, Swiatecka-Urban A. TGF $\beta 1$ inhibits Cftr biogenesis and prevents functional rescue of DeltaF508-
Cftr in primary differentiated human bronchial epithelial cells. PLoS One. 2013;8:e63167.

32. Sun $H$, Harris WT, Kortyka S, Kotha K, Ostmann AJ, Rezayat A, Sridharan A, Sanders Y, Naren AP, Clancy JP. Tgf-beta downregulation of distinct chloride channels in cystic fibrosis-affected epithelia. PLoS One. 2014;9:e106842.

33. Shamsdin SA, Alborzi A, Rasouli M, Hosseini MK, Bagheri Lankrani K, Kalani M. Alterations in Th17 and the respective cytokine levels in helicobacter pylori-induced stomach diseases. Helicobacter. 2015;20:460-75.

34. Rahimian G, Sanei MH, Shirzad H, Azadegan-Dehkordi F, Taghikhani A, Salimzadeh L, Hashemzadeh-Chaleshtori M, Rafieian-Kopaei M, Bagheri N. Virulence factors of Helicobacter pylori vacA increase markedly gastric mucosal TGF- $\beta 1$ mRNA expression in gastritis patients. Microb Pathog. 2014 67-68:1-7.

35. Wu MS, Lin JT, Hsu PN, Lin CY, Hsieh YT, Chiu YH, Hsueh PR, Liao KW. Preferential induction of transforming growth factor-beta production in gastric epithelial cells and monocytes by helicobacter pylori soluble proteins. J Infect Dis. 2007;196:1386-93.

36. Heldin $\mathrm{CH}$, Moustakas A. Role of Smads in TGF $\beta$ signaling. Cell Tissue Res. 2012:347:21-36.

37. Gomes LR, Terra LF, Wailemann RA, Labriola L, Sogayar MC. TGFbeta1 modulates the homeostasis between MMPs and MMP inhibitors through p38 MAPK and ERK1/2 in highly invasive breast cancer cells. BMC Cancer. 2012;12:26.

38. McLean S, Bhattacharya M, Di Guglielmo GM. Barrestin2 interacts with TßRII to regulate Smad-dependent and Smad-independent signal transduction. Cell Signal. 2013;25:319-31.

\section{Ready to submit your research? Choose BMC and benefit from:}

- fast, convenient online submission

- thorough peer review by experienced researchers in your field

- rapid publication on acceptance

- support for research data, including large and complex data types

- gold Open Access which fosters wider collaboration and increased citations

- maximum visibility for your research: over $100 \mathrm{M}$ website views per year

At BMC, research is always in progress.

Learn more biomedcentral.com/submissions 